\title{
Biliary tract pathology in patients with AIDS
}

\author{
R D Goldin, J Hunt
}

\section{Introduction}

Cryptosporidiosis has been recognised as an opportunistic infection of the bile ducts since 1972 when Kovatch and White described cryptosporidial cholangitis in juvenile rhesus monkeys. ${ }^{1}$ In 1983 the first cases of hepatobiliary cryptosporidiosis in patients with AIDS were reported..$^{23}$ It was suggested that the gall bladder was the source of the bile duct infections. Soon after this, infection of the biliary tree by cytomegalovirus (CMV) was described, both in association with cryptosporidial infection and on its own. ${ }^{45}$ Several papers describing the pathological findings in the biliary tract in patients with AIDS have now been published. Most of these include only small numbers of patients and it remains difficult to form an impression of the incidence of clinical disease in the biliary tree and the range of pathological findings. ${ }^{67}$ Material from the gall bladder and biliary tree is usually difficult to obtain. In the largest published study, reviewed by Cello (1992), out of 40 patients with bile duct disease 18 had a specific histopathological diagnosis. ${ }^{8}$ The diagnoses were based on biopsy specimens taken from the ampulla of Vater or post mortem findings. The commonest diagnoses made were CMV (eight cases) and cryptosporidium (six cases). Other specific diagnoses included Mycobacterium avium (three cases), Kaposi's sarcoma (one case) and lymphoma (one case). The remaining 22 cases all showed inflammatory changes.

\section{Cytomegalovirus}

This is one of the commonest organisms in patients with AIDS and frequently affects the liver and biliary tree. It is usually part of a disseminated disease: cholestatic liver function tests have been reported in one third of patients and radiological evidence of sclerosing cholangitis in 3-11\%.9 In the case of the biliary tree viral inclusions do not always have the characteristic owl's eye appearance and immunohistochemistry for CMV is extremely useful in doubtful cases.

\section{Cryptosporidial infection}

Cryptosporidial infection is a common cause of diarrhoea in patients with and without AIDS. ${ }^{10}$ Biliary tract disease, however has only been seen in patients with AIDS. ${ }^{8}$ Biliary tract abnormalities have been described in $10 \%$ of patients with intestinal cryptosporidiosis. ${ }^{11}$ The organism is a sporozoa and undergoes its complete life cycle within a single host making reinfection a possibility. ${ }^{12}$ In the bile ducts and intestines the organism is seen as small, round, basophilic structures on the luminal surface, $2-4 \mu \mathrm{m}$ in size. Although they can usually be seen easily in haemotoxylin and eosin stained sections, a Giemsa stain has been recommended. Cryptosporidial infection is associated with little inflammation, although in the bowel it has been claimed that there is an increased number of apoptotic bodies. Surprisingly, "an exuberant inflammatory reaction" has been described in association with biliary tract cryptosporidiosis in one study. ${ }^{13}$ The electron microscopic appearance of the organism is characteristic but is not necessary for diagnostic purposes. A potentially important preliminary observation is that there is electron microscopic evidence of autonomic nerve damage in the bowel and it has been suggested that this may cause disordered motility. ${ }^{14} \mathrm{~A}$ corresponding abnormality may be found in the biliary tree.

\section{Mycobacterium avium intracellulare}

Mycobacterial infections are also very common in patients with AIDS and have been identified in duodenal or ampullary biopsy specimens in a number of patients with bile duct disease. ${ }^{8}$ These have usually been caused by $M$ avium intracellulare. As in other parts of the body these are frequently found in large numbers in poorly formed granulomas and are both Ziehl Neelson and periodic acid Schiff positive.

\section{Microsporidial infection}

Microsporidia are diverse phyla. Infection by members of this group is extremely rare in patients who do not have AIDS. Enterocytozoon bienusi has mainly been associated with intestinal infection and diarrhoea ${ }^{15}$ but microsporidia have been associated with peritonitis and granulomatous hepatitis. ${ }^{16}$ It has also been found associated with sclerosing cholangitis and its importance has probably been underestimated. ${ }^{17-20}$ This has been confirmed by a recent study in which the diagnosis was made in eight patients with AIDS who had unexplained cholangitis. ${ }^{21}$ In all eight patients the organism was detected by staining bile samples, in six it was detected in duodenal biopsy specimens. Diagnosis of infection by these organisms requires active consideration by the histopathologist and electron microscopy is useful, although light microscopy is often diagnostic. ${ }^{22}$
Correspondence to: Dr R D Goldin Accepted for publication 20 January 1993 


\section{Lymphomas}

Lymphoma in patients with AIDS often affects extranodal sites. ${ }^{23}$ Primary lymphomas of the gall bladder, ${ }^{24}$ common bile duct, ${ }^{25}$ and head of pancreas ${ }^{26}$ have been recognised, although this is much less common in disseminated disease. All these reported tumours have been high grade B cell lymphomas ranging from Burkitt-like to immunoblastic tumours. Disease in the gall bladder has so far been asymptomatic; tumours of the bile ducts and the head of the pancreas have presented early with asymptomatic jaundice. ${ }^{2627}$

\section{Kaposi's sarcoma}

As is the case in the liver, disease of the gall bladder and biliary tree is seen at necropsy as part of widespread disease, although it rarely presents as a clinical problem. ${ }^{28}{ }^{29}$ Kaposi's sarcoma involving the common bile duct, however, has been associated with cholangitis and jaundice. ${ }^{27}$ This may also follow on from extensive disease of the hepatic hilum with compression of the main bile ducts..$^{30}$

\section{Clinical and radiological findings}

Gastrointestinal symptoms are common in AIDS, ${ }^{31}$ and patients may present with dysphagia, diarrhoea, or abdominal pain. In patients with right upper quadrant pain the clinician should suspect bilary disease. ${ }^{32-34}$ In one study of 64 patients with AIDS and abdominal pain the site was the right upper quadrant in 27 , and of these 17 had biliary disease $^{35}$ The pain may have been due to acalculous cholecystitis, in which CMV, cryptosporidium, and campylobacter have been implicated, ${ }^{4}$ or AIDS related sclerosing cholangitis. In the latter serum alkaline phosphatase is often several times above normal, suggesting cholestasis. ${ }^{32} 34$ In a third of cases, however, the serum liver function tests are normal $^{35}$ and jaundice is rarely seen..$^{33} 36$

The imaging features of AIDS related cholangitis are dilatation and irregularity of either the intrahepatic or extrahepatic ducts. An ultrasound scan may show intrahepatic and extrahepatic bile duct dilatation or irregularity of both the diameter of the intrahepatic ducts and the common bile duct wall, or periductular hyperechoic regions in the liver. ${ }^{1333}$ Thickening of the gall bladder wall, due to acalculous cholecystitis, can be detected $^{38}$ and the pancreatic duct may also be dilated. The sensitivity of ultrasound scanning varies from $100 \%{ }^{37}$ to $70 \%,{ }^{36}$ while the specificity approaches $85 \%{ }^{36}$ Computed tomography has not been extensively assessed but may be better than ultrasound scanning for detection of intrahepatic disease. ${ }^{33}$

Endoscopic retrograde cholangiopancreatography (ERCP) is the optimal diagnostic technique. ${ }^{13323435}$ At ERCP four abnormal cholangiographic patterns are discernible. ${ }^{36}$ The commonest is sclerosing cholangitis with ampullary stenosis in which both irregularity of the intrahepatic ducts and dilatation of the common bile duct down to the level of the ampulla are evident, with delay in drainage of contrast. Alternatively, isolated ampullary stenosis may be seen when the common bile duct is dilated but the intrahepatic ducts are not stenosed. Similarly, intrahepatic sclerosing cholangitis or extrahepatic biliary strictures may each appear in isolation. In many cases subtle changes occur in the wall of the common bile duct which looks beaded and irregular. ${ }^{39}$ More than half the patients studied have evidence of ampullary stenosis. ${ }^{33} 35-37$

Biopsy specimens of both the ampulla and bile duct can be taken at ERCP and sphincterotomy performed if indicated. ${ }^{33}$ Because of the design of the biopsy forceps, ampullary cannulation has been difficult and biliary biopsy tends only to be performed after removal of the sphincter. Duodenal and ampullary biopsy specimens were used as surrogates for biliary epithelium and biliary brush cytology specimens taken. Unfortunately, cytology has not proved diagnostic. ${ }^{35}$ Recently Teflon coated, swivel-tipped, rat toothed biopsy forceps have been marketed (Olympus FB-39Q or FB-40Q). These can be passed down the duodenoscope into the biliary tree through an intact ampulla. They are radio-opaque and incorporate a contrast injection channel and allow targeted biopsy specimens to be taken. The increased use of these forceps will advance the description of biliary pathology. Biopsy specimens from the ampulla and juxta-ampullary bile duct after sphincterotomy have shown CMV and cryptosporidium infection in $11 \%-25 \%$ and $25-35 \%$ of cases. ${ }^{35}{ }^{36}$ But these agents are also seen, albeit less frequently, in those without ampullary stenosis. ${ }^{13}$ Microsporidial infection ${ }^{17} 18$ and Candida $\mathrm{sp}^{40}$ have also been found in the biliary epithelium of these patients, but in $50 \%$ of patients a cause for the stenosis is not established. $M$ avium intracellulare has been found in duodenal biopsy specimens. The prognosis of AIDS related sclerosing cholangitis is poor. In the largest series $40 \%$ of the patients died within nine months, although biliary disease did not appear to be the cause. ${ }^{36}$

There have been two recent studies on related sclerosing cholangitis. ${ }^{20}{ }^{41}$ In the first of these, out of the 20 cases examined, 13 had cryptosporidiosis and six had active CMV infections. Compared with controls the overall survival was no worse (median 7.5 months). Surprisingly, increased age seemed to be protective in AIDS related sclerosing cholangitis. The overall findings in the second study were similar. There was a single case of microsporidial infection. The importance of actively considering the diagnosis of microsporidial infection in patients with AIDS and unexplained sclerosing cholangitis has been borne out in another recent paper. ${ }^{21}$ In eight patients with AIDS and unexplained cholangitis this diagnosis was made after thorough examination of the biliary tree.

\section{Conclusion}

CMV and cryptosporidiosis are the pathogens most regularly isolated from the biliary tree, and it is likely that with improved means of 
biopsying the biliary tree they will be diagnosed even more frequently. Several mechanisms have been proposed for the bile duct pathology seen in those patients with AIDS in whom an opportunistic infection is not found. Human epithelial cells isolated from the large and small bowel have been shown to allow permissive replication of HIV in vitro, ${ }^{42}$ and in situ hybridisation studies have detected HIV RNA in hepatocytes. ${ }^{43}$ So far infection of biliary epithelial cells has not been shown. Patients with AIDS may have repeated episodes of portal bacteraemia and this may be important. Class II HLA antigens have been shown on the bile duct epithelium in five out of 10 patients in whom this has been sought and this may also be important in the pathogenesis of bile duct damage. ${ }^{44} 45$

1 Kovatch RM, White JD. Cryptosporidiosis in two juvenile rhesus monkeys. Vet Pathol 1972;9:426-40

2 Pitlik S, Fainstain D, Garza D, et al. Human cryptosporidiosis: Spectrum of disease: Report of six cases and review of the literature. Arch Intern Med 1983;143:2269-75

3 Guarda LA, Stein SA, Clearly KA, Orodenz NG. Human cryptosporidiosis in the acquired immunodeficiency syndrome. Arch Pathol Lab Med 1983;107:562-6.

4 Blumberg RS, Kelsey P, Peppone T, et al. Cytomegalovirus and cryptosporidium-associated acalculous gangrenous cholecystitis. Am $\mathcal{f}$ Med 1984;76:1118-23.

5 Kavin H, Jonas RB, Chowdhury L, Kabins A. Acalculous cholecystitis and cytomegalovirus infection in the acquired immunodeficiency syndrome. Ann Int Med acquired immu

6 Bach N, Theise N, Schaffner F. Hepatic histopathology in the acquired immunodeficiency syndrome. Semin Liver Dis 1992;12:205-12.

7 Wilkins MJ, Lindley R, Dourakis SP, Goldin RD. Surgical pathology of the liver in AIDS. Histopathology 1991;18 459-64.

8 Cello JP. Human immunodeficiency virus-associated biliary tract disease. Semin Liver Dis 1992;12:213-8.

9 Jacobson MA, Cello JP, Sande MA. Cholestasis and disseminated cytomegalovirus disease in patients with the acquired immunodeficiency syndrome. $A m \quad f \mathrm{Med}$ 1987;84:546-9.

10 Rene E, Marchie C, Requier B, et al. Intestinal infections in patients with the acquired immunodeficiency syndrom: A prospective study in 132 patients. Dig Dis $S c i$ 1989;34:773-80.

11 Soave R, Armstrong D. Crytposporidium and cryptosporidiosis. Rev Infect Dis 1986;8:1012-23.

12 Current WL, Reese NC. A comparison of endogenous development of three isolates of cryptosporidium in suckling mice. $\mathcal{F}$ Protozool 1986;33:98-108.

13 Teixidor HS, Godwin TA, Ramirez EA. Cryptosporidiosis of the biliary tract in AIDS. Radiology 1991;180:51-6.

14 Gazzard BG. Diarrhoea in human immunodeficiency virus antibody-positive patients. Semin Liver Dis 1992 . 12:154-66.

15 Peacock CK, Blanshard C, Tovey DG, et al. The histological diagnosis of microsporidiosis in patients with AIDS. f Clin Pathol 1991;44:558-63.

16 Terada S, Reddy R, Jeffers LJ, et al. Microsporidian hepatitis in the acquired immunodeficiency syndrome. Ann Int Med 1987;107:61-2.

17 McWhinney P, Nathwani D, Green ST, Boyd JF, Forrest J. Microsporidiosis detected in association with AIDSrelated sclerosing cholangitis. AIDS 1991;5:1394-5.

18 Beaugerie L, Teilhac MF, Deloul AM, et al. Cholangiopathy associated with Microsporidia infection in the common bile duct mucosa in a patient with HIV the common bile duct mucosa in a pation.

19 Pol S, Romana C, Richard S, et al. Enterocytozoon bieneusi infection in acquired immunodeficiency syndrome-related sclerosing cholangitis. Gastroenterology
1992;102:1778-81

20 Forbes A, Blanshard C, Gazzard B. Natural history of AIDS related sclerosing cholangitis: a study of 20 cases. Gut 1993;34:116-21.

21 Pol S, Romana C, Richard S, et al. Microsporidia infection in patients with the humanh immunodeficiency virus and unexplained cholangitis. $N$ Engl $f \mathrm{Med}$ 1993;328:95-9.

22 Lucas SB, Papadaki L, Conlon C, et al. Diagnosis of intestinal microsporidiosis in patients with AIDS. $f$ Clin Pathol 1989;42:885-7.

23 Knowles DM, Chamulak GA, Subar M, et al. Lymphoid neoplasia associated with the acquired immunodeficiency syndrome (AIDS). Ann Int Med 1988; 108:744-53.

24 Ziegler JL, Beckstead JA, Volbereing PA, et al. NonHodgkin's lymphoma in 90 homosexual men. $N$ Engl $\mathcal{f}$ Med 1984;311:565-9.

25 Kaplan LD, Kahn J, Jacobson M, et al. Primary bile duct lymphoma in the acquired immunodeficiency synlymphoma in the acquired immunodef

26 Brivet F, Coffin B, Bodes P, et al. Pancreatic lesions in AIDS. Lancet 1987;ii:570-1.

27 Herndier BG, Friedman SL. Neoplasms of the gastrointestinal tract and hepatobiliary system in acquired immunodeficiency syndrome. Semin Liver Dis 1992;12. 128-41.

28 Guarda LA, Luna MA, Smith JR, et al. Acquired immunodeficiency syndrome: Post mortem findings. Am f Clin Pathol 1984;6:165-717.

29 Friedman SL, Wright TL, Altman DF. Gastrointestinal Kaposi's sarcoma in patients with acquired immunodeficiency syndrome. Endoscopic and autopsy findings. ficiency syndrome. Endoscopic

30 Niedt GW, Schinella RA. Acquired immunodeficiency syndrome: Clinicopathologic study of 56 cases. Arch Pathol Lab Med 1985;109:727-34.

31 Fauci A, Macher A, Longo D, et al. Acquired immunodeficiency syndrome: epidemiologic, clinical, immunologic and therapeutic considerations. Ann Int Med 1984, 100:92-106.

32 Roulot D, Valla D, Brun-Vezinet F, et al. Cholangitis in the acquired immunodeficiency syndrome: report of two cases and review of the literature. Gut 1987;28: $1653-60$

33 Dolmatch B, Laing F, Federle M, Jeffrey R, Cello J AIDS-related cholangitis: Radiographic findings in nine patients. Radiology 1987;163:313-16

34 Dowsett JF, Miller $\mathrm{R}$, Davidson $\mathrm{R}$, et al. Sclerosing cholangitis in acquired immunodeficiency syndrome. Scand $\mathcal{F}$ Gastroenterol 1988;23:1267-74.

35 Thuluvath PJ, Connolly GM, Forbes A, Gazzard BG. Abdominal pain in HIV infection. $Q f$ Med 1991; 78:275-85.

36 Cello J. Acquired immunodeficiency syndrome cholangiopathy: spectrum of disease. $A m \mathcal{F}$ Med 1989; 86:539-46.

37 McCarty M, Choudhri A, Helbert M, Crofton M Radiological features of AIDS related cholangitis. Clin Radiol 1989;40:582-5.

38 Romano AJ, vanSonnenberg E, Casola G, et al. Gallbladder and bile duct abnormalities in AIDS: sonographic findings in eight patients. $A m$ f Radiol 1988;150:123-7.

39 Margulis S, Honig C, Soave R, Govoni A, Mouradian J, Jacobson I. Biliary tract obstruction in the acquired immunodeficiency syndrome. Ann Int Med 1986;105: 207-10.

40 Cockerill FR, Hurley DV, Malagelada JF, et al. Polymicrobial cholangitis and Kaposi's sarcoma in blood product transfusion-related acquired immunodeficiency syndrome. $A m \neq \mathrm{Med} 1986 ; 80: 1237-41$.

41 Bouche H, Housett C, Dumont F, et al. AIDS-related cholangitis: diagnostic features and course in 15 patients. F Hepatol 1993;17:34-9.

42 Moyer MP, Huot RI, Ramirez A, et al. Infection of human gastro-intestinal cells by HIV-1. AIDS Res Hum Retroviruses 1990;6:1409-14.

43 Cao Y, Detroit D, Thomas PA, Yaoxing H, Mirabile $M$ Ho D. Identification of HIV-1 in the liver of patients with AIDS. AIDS 1992;6:65-70.

44 Viteri AL, Green JF. Bile duct abnormalities in the acquired immunodeficiency syndrome. Gastroenterology 1987;92:2014-18.

45 Sieratzki J, Thung SN, Gerber MA, et al. Major histocompatibility antigen expression in the liver in acquired immunodeficiency syndrome. Arch Pathol Lab Med 1987;111:1045-9. 